\title{
LER LEVANTANDO A CABEÇA: CAMINHOS E DESCAMINHOS DA LEITURA LITERÁRIA NA EDUCAÇÃO BÁSICA
}

\author{
Maria Paula Parisi Lauria \\ mpaulaparisilauria@gmail.com
}

"A literatura não corrompe nem edifica, mas humaniza em sentido profundo, porque faz viver." Antonio Candido

Ao abrir o texto "Escrever a leitura", presente na obra $O$ rumor $d a$ língua, Roland Barthes lança ao leitor duas perguntas entrelaçadas: "Nunca lhe aconteceu, ao ler um livro, interromper com frequência a leitura, não por desinteresse, mas, ao contrário, por afluxo de ideias, excitações, associações? Numa palavra, nunca lhe aconteceu ler levantando a cabeça?” (BARTHES, 2004, p.26)

Essa leitura apaixonada e inquieta, um forte indicador de que o leitor está travando com o texto um diálogo efetivo, parece ser hoje um ponto avançado quando falamos do processo de formação de leitores, sobretudo no campo escolar, terreno delicado de tensões entre a sedução e o afastamento do ato de ler. O que mais poderia querer um bom professor de literatura do Ensino Médio, quando ele mesmo é um leitor apaixonado, senão perceber que ao menos alguns de seus alunos dão pistas de que estabeleceram com a leitura literária um jogo de produção de sentidos em que operam não só o processamento do texto, a compreensão leitora e a contextualização, mas também uma poderosa força de atração que, conforme nomeia Barthes, os leva a cortar o texto, escrever mentalmente sua leitura, voltar ao livro e dele se nutrir? 
Embora estejamos em geral distanciados do processo tão particular que permeia a leitura de nossos alunos - é de se perguntar que local escolhem para ler, em que posição leem, atravessados por que sons e por quais outras forças de atração - o mais comum é ouvirmos, sobretudo entre adolescentes, que o livro solicitado pelo professor não foi lido (nem comprado ou emprestado ou baixado da internet), que foi esquecido em casa justo no dia em que seria trabalhado na escola, que foi lido "mais ou menos", que algumas partes foram puladas, que os olhos até percorreram as palavras, mas que pouco ficou desse percurso. O mais corrente, enfim, é termos notícia de que o aluno médio esteve longe de estabelecer com o texto o que Mikhail Bakhtin chama, quando trata da relação do ouvinte com o discurso, de "atitude responsiva ativa", segundo a qual receber e compreender a significação linguística implica fazer negociações de sentido, numa constante colaboração entre autoria e recepção:

De fato, o ouvinte que recebe e compreende a significação (linguística) de um discurso adota simultaneamente, para com este discurso, uma atitude responsiva ativa: ele concorda ou discorda (total ou parcialmente), completa, adapta, apronta-se para executar, etc. e esta atitude do ouvinte está em elaboração constante durante todo o processo de audição e de compreensão desde o início do discurso, às vezes já nas primeiras palavras emitidas pelo locutor.(BAKHTIN, 1992, p. 290)

Adaptada ao leitor e não somente ao ouvinte, essa atitude estaria na base de um autêntico trabalho de apropriação de um gênero complexo, gerado pela especificidade própria do texto literário, que conta, em maior ou menor grau, com um lapso de tempo entre a leitura e a produção de sentidos, em uma espécie de compreensão responsiva muda. Conforme lembra esse autor, "os gêneros secundários da comunicação verbal, em sua maior parte, contam precisamente com esse tipo de compreensão responsiva de ação retardada. O que acabamos de expor vale também, mutatis mutandis, para o discurso lido ou escrito." (BAKHTIN, 1992, p. 291).

Ainda que nem sempre o trabalho com o texto literário tenha visado a essa dinâmica interação entre leitor-autor-texto, e que as explanações sobre os movimentos literários, em que se inserem dados autores e obras tidos como canônicos tenham ganhado relevo no que comumente se chama de aula de literatura, é inegável que esse texto específico sempre frequentou as salas de aula brasileiras, nos diferentes níveis de ensino. Tendo como apoio as antologias e os florilégios do século XIX, nos quais só figuravam textos literários, e de autores mortos, as aulas de Português valiam-se da literatura em drágeas para a promoção de lições de moral e de bons costumes, para o treino da leitura em voz alta, para o dissecamento 
dos períodos simples e compostos, base de uma análise sintática que não tinha como foco atuar em prol da construção de sentido na leitura do texto em questão. Tal tradição, de se trabalhar exclusivamente com o texto literário, preferencialmente de autores mortos, foi muito bem traduzida pela Antologia Nacional, obra em volume único que teve vida longa nas escolas do antigo ginasial, de 1895 até os anos 1960.

A primazia do texto literário nos manuais didáticos, respaldada pelos programas oficiais, se manteve mesmo quando, nos anos 1950, os volumes únicos passaram a dar lugar a coleções seriadas, que recortavam, dos cânones da literatura de expressão portuguesa, amostras descontextualizadas de autores consagrados:

\footnotetext{
O programa de português, no chamado curso ginasial, preconizava para a série inicial a leitura de excertos breves e fáceis de prosadores e poetas brasileiros dos dois últimos séculos', recomendando que se lessem progressivamente excertos e textos em prosa e verso de autores brasileiros e portugueses dos séculos XVIII e XIX. Em comum para todas as séries, havia o vocabulário, a exposição oral e os exercícios escritos de redação. A ortografia e a declamação de pequenos poemas eram prerrogativas das duas primeiras séries. (LAURIA, 2002, p. 137)
}

De acordo com essa autora, nos anos 1960, algumas obras de apoio às aulas de língua materna começaram a abrir espaço para textos literários de autores contemporâneos e para o início de um trabalho de compreensão leitora mais palpável e sistematizado. A expressão oral contaria com forte apoio da leitura de textos descritivos, narrativos e dissertativos - conforme a série. Nas duas primeiras séries do ginásio, segundo as indicações para o curso de Português que acompanham a Lei de Diretrizes e Bases de 1961, estudar-se-iam autores brasileiros dos dois últimos séculos e, nas duas últimas, prosadores e poetas modernos, brasileiros e portugueses. Deuse, nesse período a entrada de autores contemporâneos à publicação de livros didáticos importantes, como Português através de textos, de Magda Soares, com destaque para cronistas do porte de Carlos Drummond de Andrade, Fernando Sabino, Rubem Braga, Paulo Mendes Campos e poetas como Cecília Meireles, Manuel Bandeira, Vinicius de Moraes, Jorge de Lima, Henriqueta Lisboa.

Se, nesse período, recomendava-se que o professor contextualizasse os textos, sobretudo se fossem fragmentos de uma obra maior, mais adiante, a partir dos anos 1970, deu-se a entrada, sobretudo nos livros didáticos destinados ao atual Ensino Fundamental II, de textos midiáticos (notícias, quadrinhos, charges), que definitivamente abalaram de vez o legado da exclusividade do texto literário no trabalho em sala de aula, não necessariamente primando pelas explicitações de seu contexto de produção. 
Os Parâmetros Curriculares Nacionais $(\mathrm{PCN})$, particularmente os voltados para o ensino de Língua Portuguesa publicados a partir de 1996, ainda que tenham proporcionado muitos avanços no campo da leitura e da produção de textos, vieram coroar o processo de diversificação de gêneros e linguagens nos textos na sala de aula, o que certamente trouxe como consequência a diminuição do tempo didático voltado ao trabalho com o texto literário. Para completar o quadro, os materiais didáticos em geral consolidaram uma cultura metonímica no tratamento da literatura na escola. Substitui-se a parte pelo todo, sendo que a parte escolhida para figurar nos livros escolares nem sempre faz jus ao todo e o todo nem sempre é lido em suas partes e muito menos sua leitura é compartilhada por alunos e professores. Em vez de uma discussão amparada pela leitura efetiva da obra literária, a escola muitas vezes tem optado por instrumentos de controle do pretensamente lido: as famosas "provas de livro", os questionários insossos, os roteiros de leitura estandartizados. Ferramentas para medir a "qualidade" da leitura, essa fugidia atividade individual que, em princípio, não deixa marcas e tende a escapar de medições objetivas.

Tendo como pressuposto que a escola tem tomado para si, para o bem e para o mal, a tarefa de dar um tratamento a essa forma específica de conhecimento que é a literatura, e que hoje se considera que o texto literário apresenta propriedades composicionais capazes de serem mostradas, discutidas e consideradas em sua leitura, cabem algumas outras perguntas que nos fazem levantar a cabeça:

Em que medida a concepção de trabalho com a leitura literária que hoje atravessa a educação básica, proposto por documentos oficiais, tem contribuído para formar leitores desejantes e reflexivos, capazes de ser fisgados pelas temáticas, formas composicionais e escolhas linguísticas operadas pela autoria?

Até que ponto o professor de Língua Portuguesa que já está em sala de aula conhece, lê e aproveita, em sua prática, indicações presentes em documentos oficiais voltados para seu fazer didático no nível em que atua?

Para responder a primeira pergunta, há que se considerar que os documentos oficiais costumam refletir as concepções teóricas que seacredita serem as mais adequadas para as práticas educativas de determinado espaço e tempo. Em sua elaboração, embora haja um grupo diretamente responsável pela redação, é desejável que vários segmentos (professores, coordenadores, supervisores, gestores, especialistas da área, acadêmicos) sejam ouvidos e considerados, a fim de que esse documento que vai, de certa forma, balizar as ações educativas em dada disciplina, possa refletir uma pluralidade de vozes que, apesar de suas divergências, é capaz de propor alguns encaminhamentos em comum embasados em concepções dominantes. 
No caso brasileiro, um dos documentos oficiais de maior importância nas duas últimas décadas, os Parâmetros Curriculares Nacionais (PCN), tiveram uma penetração diferente nos diversos níveis de ensino da educação básica, a partir de sua proposição, iniciada em 1996. Ainda que a maioria deles tenha tido um impacto direto na formação de novos docentes, na capacitação de professores em serviço e na produção de livros didáticos, os documentos voltados para o Ensino Médio travaram com os do Ensino Fundamental I e II uma coesão um tanto afrouxada. Enquanto os PCN voltados ao Ensino Fundamental abraçaram fortemente a concepção sócio-interacionista de linguagem, com a noção bakhtiniana de discurso (e seus gêneros orais e escritos) permeando as ações ligadas aos quatro eixos para o ensino de Língua Portuguesa (leitura, produção de textos, oralidade e conhecimentos linguísticos), os PCNEM, publicados em 200o, por sua vez, deram relevo ao estabelecimento de competências e habilidades de caráter fortemente interdisciplinar, em consonância com a proposta do ENEM ( 5 eixos cognitivos, 30 competências, 120 habilidades). Os PCNEM, na parte voltada à Língua Portuguesa, incorporaram algumas dessas competências e elegeram quatro delas para compor a proposta da disciplina:

- Considerar a Língua Portuguesa como fonte de legitimação de acordos e condutas sociais e como representação simbólica de experiências humanas manifestas nas formas de sentir, pensar e agir na vida social;

- Analisar os recursos expressivos da linguagem verbal, relacionando textos/contextos, mediante a natureza, função, organização, estrutura, de acordo com as condições de produção/recepção (intenção, época, local, interlocutores participantes da criação e propagação de ideias e escolhas);

- Confrontar opiniões e pontos de vista sobre diferentes manifestações da linguagem verbal;

- Compreender e usar a Língua Portuguesa como língua materna, geradora de significação e integradora da organização do mundo e da própria identidade. (BRASIL, 2000, p.20-2)

Como se vê, dessas quatro grandes competências, aquela que nos leva a inferir que se pode estar aludindo à literatura é a segunda. Ainda assim, não há uma referência direta à especificadade do trabalho com o texto literário. Há, isso sim, uma menção ao trabalho com o texto escrito, de diferentes procedências, e uma aproximação ao dialogismo e ao sóciointeracionismo.

Ao final da parte dedicada à Língua Portuguesa, o leitor do documento depara-se com o seguinte trecho: 
Ao ler este texto, muitos educadores poderão perguntar onde está a literatura, a gramática, a produção de texto escrito, as normas. Os conteúdos tradicionais foram incorporados por uma perspectiva maior, que é a linguagem, entendida como um espaço dialógico, em que os locutores se comunicam. Nesse sentido, todo conteúdo tem seu espaço de estudo, desde que possa colaborar para as competências em questão. (BRASIL, 2000, p.23)

Ao colocar no mesmo patamar eixos de trabalho com a Língua Portuguesa (literatura, gramática, produção de texto escrito) e normas (uma provável alusão ao ensino da gramática normativa) o documento assume certa falta de rigor no entendimento do que devam ser as linhas mestras que conduzirão as atividades em sala de aula e subordina os conteúdos (mais uma vez misturados a eixos de trabalho) à linguagem e às competências: dá o recado, portanto, de que os conteúdos tradicionais são válidos desde que sirvam a desenvolver competências gerais dentro dessa grande linguagem que é a Língua Portuguesa.

Nesse campo, os PCN de Fundamental I e II, embora acusados de empregar uma linguagem pouco acessível ao professor médio, foram mais claros. No item A especificidade do texto literário, lê-se:

É importante que o trabalho com o texto literário esteja incorporado às práticas cotidianas de sala de aula, visto tratar-se de uma forma específica de conhecimento. Essa variável de constituição da experiência humana possui propriedades compositivas que devem ser mostradas, discutidas e consideradas quando se trata de ler as diferentes manifestações colocadas sob a rubrica geral de texto literário. (...)(BRASIL, 1998, p. 32)

Os documentos oficiais lançados em 1996 (PCN de FI e FII, com volumes específicos para cada disciplina) trouxeram à educação brasileira muitos desdobramentos: tiveram impacto direto sobre a produção dos livros didáticos (cuja aprovação pelo MEC, no Programa Nacional do Livro Didático, esteve sempre vinculada ao alinhamento teórico proposto nos $\mathrm{PCN}$ ); provocaram a necessidade de capacitação dos professores para lidarem com paradigmas que vinham lentamente se instalando na educação brasileira desde os anos 1980; levaram a mudanças curriculares importantes nos cursos de Língua Portuguesa, colocando em cena os gêneros textuais, elemento-chave na alimentação dos quatro eixos de trabalho com LP: leitura, produção de textos, oralidade e conhecimentos linguísticos.

Diante da crítica de que eram muito conceituais e pouco práticos, surgiram os PCN em Ação, com propostas concretas para o trabalho em sala de aula nas diferentes disciplinas.

Lançados em 200o, quatroanos depois, portanto, em relaçãoà primeira geração de PCN, os PCNEM não tiveram desdobramentos semelhantes 
aos de seus antecessores: a proposta voltada para o desenvolvimento de competências e habilidades não foi de fato incorporada ao cotidiano escolar da maioria das escolas; o documento foi acusado de uma certa "vaguidão específica" (empresto a expressão utilizada por Millôr Fernandes em uma crônica em que se reproduz um diálogo entre duas mulheres - ambas sabem do que estão falando, mas não há referentes), o que gerou a necessidade de novos documentos, na busca por nortear professores desnorteados; o PNLD para o EM só teve incício em 2004, com distribuição parcial de livros apenas em 2005, o que nos leva a supor que a vinculação entre o material didático para o EM e os documentos voltados para o nível foi frouxa a ponto de o cotidiano escolar, com o uso dos livros didáticos, não ser tão impactado tal como aconteceu com o Ensino Fundamental.

Em 2002, foi lançado o PCN+, um volume de orientações educacionais complementares aos $\mathrm{PCN}$, do qual participei como consultora de Língua Portuguesa, juntamente com outros especialistas de disciplinas que compunham a área de Linguagens, Códigos e suas Tecnologias . A solicitação do MEC nos punha numa situação delicada: de um lado, nos foi expressamente dito que não podíamos negar a base de competências e habilidades proposta no documento anterior (o que particularmente achava um problema); de outro lado, era preciso apresentar propostas concretas para a sala de aula. Enfim, a encomenda pressupunha um resgate e uma ampliação do documento anterior (por isso a opção por desdobrar as quatro grandes competências em outras e esclarecer uma série de conceitos-chave, específicos da área de Língua Portuguesa). Pressupunha ainda um direcionamento semelhante àquele proposto nos PCN em Ação (Ensino Fundamental), o que nos levou a rechear o texto com propostas de trabalho para a sala de aula, não raras vezes com referência à literatura, valendo-nos de nossa experiência como professores do Ensino Médio. Vale lembrar, quanto às condições de produção, que o texto desse documento foi produzido em curto espaço de tempo e ficou bem longe de refletir qualquer discussão mais aprofundada sobre novos encaminhamentos (as únicas interlocuções eram com os pares de área e também com a coordenação).

Em 2006, foram lançadas as Orientações Curriculares para o Ensino Médio, documento que, segundo informação presente no site do MEC, foi constituído a partir de outras bases, com ampla discussão com as equipes técnicas dos Sistemas Estaduais de Educação, professores e alunos da rede pública. O documento, cujas bases teriam sido plantadas a partir de 2004, redirecionou completamente a discussão em torno do Ensino Médio, abandonando a matriz de competências e habilidades e 
estabelecendo, para a disciplina Língua Portuguesa, dois grandes eixos curriculares: Conhecimentos de Língua Portuguesa e Conhecimentos de Literatura. Os textos relativos a esses dois grandes eixos foram produzidos por uma tríade de professores de diferentes universidades, e lidos criticamente por nomes reconhecidos no campo do ensino de língua portuguesa, o que certamente possibilitou um diálogo qualitativo, do qual os documentos anteriores para o Ensino Médio certamente não se beneficiaram.

Nesse documento, que trava um diálogo com trechos do PCN e do $\mathrm{PCN}+$, fazendo-lhes críticas e realinhando algumas posições, a literatura ganha status de disciplina, na medida em que está irmanada a itens como conhecimentos relativos a língua portuguesa, língua estrangeira, espanhol, artes e educação física. Trata-se de um documento que procura esclarecer conceitos, inclusive o de literatura (arte com palavras), diferente dos anteriores destinados ao nível, que parecem partir de pressupostos, mais do que postos. Certamente a equipe que o produziu participou de uma situação política diferente daquela que levou aos documentos anteriores, o que possibilitou rever a pertinência de se considerar o eixo de competências e habilidades como norteador do currículo. Cabe perguntar, entretanto, por que não ganhou visibilidade, apesar de suas inegáveis qualidades e esclarecimentos, na interlocução com os professores, e das muitas possibilidades que oferece para estruturar, qualitativamente, o trabalho com a língua e a literatura no Ensino Médio. Ainda que figure no site do MEC, atualmente, como o documento que norteia as bases da área de Linguagens, Códigos e suas Tecnologias (ao lado dos documentos de Ciências da Natureza, Matemática e suas Tecnologias e de Ciências Humanas e suas Tecnologias) seu conteúdo não parece circular nas escolas, a não ser indiretamente, por meio dos pressupostos necessariamente adotados nos livros didáticos aprovados pelo MEC.

E é nesse momento que retomo a segunda pergunta:

Até que ponto o professor de Língua Portuguesa que já está em sala de aula conhece, lê e aproveita, em sua prática, indicações presentes em documentos oficiais voltados para o nível em que atua?

Apesar de os documentos oficiais serem em princípio voltados para o professor, uma minoria se vale deles para nortear o trabalho com conteúdos e procedimentos que desenvolverão junto aos alunos. Fica a impressão de que o professor que já está em sala de aula (sobretudo os que já têm alguns anos de experiência) usufrui apenas indiretamente das orientações curriculares presentes nos documentos oficiais, seja por meio de materiais didáticos que adota, seja pelo contato com divulgadores das concepções presentes nos documentos oficiais. A não 
ser que participe de capacitações específicas, oferecidas pela escola em que atua, ou que volte a ter contato com a universidade, ao investir em novos estudos (aperfeiçoamentos, especializações, pós-graduações), o professor dificilmente tomará a iniciativa de voltar-se, por ele mesmo, aos documentos oficiais. Parece ter sido mais frequente que as novas gerações de professores, já formadas a partir dos paradigmas amplificados pelos PCN e praticados nos cursos que os formaram, levem para a sala de aula muitas das orientações ali presentes.

Desses professores mais antigos, a impressão que se tem, confirmada por alguns estudos, é a de que ao longo de sua carreira vão se constituindo como palimpsestos, sendo sua formação inicial e suas referências afetivas de docência (tão importantes nos primeiros anos do ofício) aos poucos recobertas por novas camadas, motivadas pela própria experiência com os alunos, pelos novos conhecimentos, e, claro, pelas linhas de força que vão se constituindo em seu campo de atuação e que, bem ou mal, são levados a acompanhar.

Conforme aponta Maurice Tardif, os saberes profissionais dos docentes são variados e heterogêneos, em pelo menos dois sentidos que nos interessam mais de perto nesta discussão:

\begin{abstract}
Em primeiro lugar, eles provêm de diversas fontes. Em seu trabalho, um professor se serve de sua cultura pessoal, que provém de sua história de vida e de sua cultura escolar anterior; ele também se apóia em certos conhecimentos disciplinares adquiridos na universidade, assim como em certos conhecimentos didáticos e pedagógicos oriundos de sua formação profissional; ele se apóia também naquilo que podemos chamar de conhecimentos curriculares veiculados pelos programas, guias e manuais escolares; ele se baseia em seu próprio saber ligado à experiência de trabalho, na experiência de certos professores e em tradições peculiares ao ofício de professor. Os saberes profissionais também são variados e heterogêneos porque não formam um repertório de conhecimentos unificado, por exemplo, em torno de uma disciplina, de uma tecnologia ou de uma concepção do ensino; eles são, antes, ecléticos e sincréticos. Um professor raramente tem uma teoria ou uma concepção unitária de sua prática; ao contrário, os professores utilizam muitas teorias, concepções e técnicas, conforme a necessidade, mesmo que pareçam contraditórias para os pesquisadores universitários. Sua relação com os saberes não é de busca de coerência, mas de utilização integrada no trabalho, em função de vários objetivos que procuram atingir simultaneamente. (TARDIF, 2000, p. 14-15)
\end{abstract}

O ensino de Língua Portuguesa hoje requer do professor um grande fôlego, não só para estabelecer uma interação efetiva com os alunos, como também para entrelaçar e dar sentido aos eixos de trabalho da disciplina, que apontam sobretudo para a formação do leitor e do produtor de textos capaz de se colocar como efetivo usuário dos recursos da língua. Para tanto, é necessário que o Ensino Médio acione o que foi plantado no Ensino 
Fundamental - e sabemos que as lacunas, em alguns nichos, ainda são grandes - sobretudo em relação aos conhecimentos da língua portuguesa e ao trabalho com a leitura em diversos domínios da comunicação e, em particular, no domínio da literatura.

A leitura, para Catherine Mazauric, "passa por um lugar de construção de identidade pessoal”, o que pressupõe uma relação com o outro e com o mundo. Citando Nathalie Heinich, essa autora ressalta que a construção da identidade, ainda que muito íntima, não é uma ação solitária, que remeteria o sujeito a ele mesmo; ao contrário, esse processo é interativo, na medida em que coloca o sujeito em relação com outros sujeitos, grupos, instituições, corpos, objetos, palavras. Para essa autora,

(...) encarar a leitura como um lugar de elaboração identitária, e portanto de uma interação, parece-nos particularmente útil em se tratando de didática da leitura literária, à medida que esta precisa levar em conta justamente o que se sobressai às prescrições do texto, aos percursos do leitor na ficção e na língua, às múltiplas posturas que ele pode adotar, aos trajetos coletivos de um grupoclasse e à mediação de um professor, ele também sujeito leitor em busca de sua satisfação na forma de identidades múltiplas (pessoal, profissional etc.)." (MAZAURIC, 2013, p. 92)

Como a escola pode promover a formação identitária pela leitura literária, dando espaço para as subjetividades, sem abrir mão de trabalhar, objetivamente, as obras consideradas representativas na formação de uma identidade maior, universal ou nacional?

De fato, conforme propõe Annie Rouxel, se a principal finalidade do ensino da literatura é "a formação de um sujeito leitor livre, responsável e crítico”, é preciso considerar três componentes na leitura praticada na escola: a atividade do aluno como sujeito leitor que compõe, junto com seus colegas, uma comunidade interpretativa; a literatura abordada (textos e obras) e, de fundamental importância, a ação do professor que faz escolhas didáticas e pedagógicas. (ROUXEL, 2013, p. 20)

Como o professor pode, no dizer dessa autora, convidar o aluno para a aventura interpretativa e seus riscos sem abrir mão de fazer da leitura literária um lugar em que são mobilizadas três espécies de saberes: sobre os textos, sobre o próprio leitor, sobre o léxico?

Se, conformeaponta ela, na primeira etapa do Ensino Fundamental, as crianças tendem a expressar abertamente suas emoções e o professor luta para que voltem ao texto, mais adiante os adolescentes resistem a revelar sua intimidade, por pudor ou vergonha de expor suas interpretações, e muitas vezes se prendem ao senso comum, sem arriscar observações potencialmente sustentadas pelo texto. 
Vincent Jouve propõe que se coloque a leitura subjetiva "no coração dos cursos de literatura", pois acredita que acionar o interesse do aluno por meio de um objeto que fale de e com esse leitor é um caminho profícuo para que a escola chegue a uma de suas finalidades essenciais, que é completar o saber do aluno sobre o mundo:

Toda leitura tem, como se sabe, uma parte constitutiva de subjetividade. Para muitos, trata-se de uma realidade negativa a implicação pessoal do leitor no texto, a qual contém em germe todos os desvios possíveis, indo do simples erro de leitura ao contrassenso mais flagrante. Gostaria de nuançar esse ponto de vista (sem, contudo, a ele me opor frontalmente), atendo-me aos aspectos positivos dessa reapropriação parcial do texto pelo leitor. Com efeito, cada um projeta um pouco de si na sua leitura, por isso a relação com a obra não significa somente sair de si, mas também retornar a si. A leitura de um texto é sempre a leitura do sujeito por ele mesmo, constatação que, longe de problematizar o interesse do ensino literário, ressalta-o.( JOUVE, 2013, p. 53)

Sem deixar de reconhecer que a subjetividade por vezes opera a favor do leitor, pois os textos literários oferecem muitos "lugares de incerteza" que solicitam a criatividade do sujeito como que completando as cenas, e não raras vezes contra o leitor, pois por não ter se mantido na letra o sujeito arrisca inferências capazes de produzir leituras erradas, esse autor acredita que a confrontação do leitor consigo mesmo é uma das dimensões maiores da leitura, o que o leva a crer que deva ser introduzida no ensino:

Proponho um percurso em três tempos.

A primeira etapa consistiria em partir da relação pessoal com o texto. Tratar-seia, após a leitura de um dado trecho, de perguntar aos alunos o seguinte: como estão representados o cenário, os objetos, as personagens? Como estas reagem à situação no plano afetivo e moral? Os alunos podem se identificar com elas? O que eles compreendem do texto? O que acham interessante?

Uma segunda etapa consistiria em confrontar as reações dos alunos com os dados textuais. Poder-se-ia, por exemplo, partir de respostas contraditórias para ver se o texto permite ou não respostas categóricas. O desafio é mediar aquilo que vem do texto e o que cada leitor acrescenta. Distinguir-se-ão igualmente, entre as configurações subjetivas, aquelas que são compatíveis com o que diz o texto e aquelas que não o são.

A última etapa consistirá em interrogar as reações subjetivas dos alunos (sobretudo quando elas não são requisitadas pelo texto, ou até quando elas o contradizem). De onde vêm suas representações? Por que se identificam com certas passagens? Por quais razões julgam certo ato positivo ou negativo etc? A finalidade do exercício é mostrar que a leitura não é somente a ocasião de enriquecer o saber do mundo; ela permite também aprofundar o saber sobre si.(JOUVE, 2013, p. 61-2) 
Esses procedimentos, aparentemente simples, mas tantas vezes solapados em um cotidiano escolar que dá mais importância ao preenchimento de questionários e à feitura de avaliações de leitura, parece ratificar o que sugere Roland Barthes no texto que serviu de mote a este artigo:

Abrir o texto, propor o sistema de sua leitura, não é apenas pedir e mostrar que podemos interpretá-lo livremente: é principalmente, e muito mais radicalmente, levar reconhecer que não há verdade objetiva ou subjetiva na leitura, mas apenas verdade lúdica: e, ainda mais, o jogo não deve ser entendido como uma distração, mas como um trabalho - do qual, entretanto, se houvesse evaporado qualquer padecimento: ler é fazer nosso corpo trabalhar (sabe-se desde a psicanálise que o corpo excede em muito nossa memória e nossa consciência) ao apelo dos signos do texto, de todas as linguagens que o atravessam e que formam como que a profundeza achamalotada das frases. (BARTHES 2004, p. 29)

Apesar das muitas cabeças que se levantam dos livros e a eles não voltam, em busca de outras páginas (de Facebooks, Instagrans e blogs), à procura de tensões que não a de moçoilas enamoradas e seus amores impossíveis mas aquelas de comentários cotidianos, jogos virtuais e combates online, ainda é preciso acreditar que as aulas de literatura podem levar à efetiva formação de um sujeito leitor, capaz de levantar a cabeça para dar espaço à subjetividade, no bom sentido barthesiano.

\section{REFERÊNCIAS BIBLIOGRÁFICAS}

BAKHTIN, Mikhail. Estética da criação verbal. São Paulo: Martins Fontes, 1992.

BARTHES, Roland. O rumor da língua. Trad. Mario Laranjeira. $2^{\underline{a}}$ ed. São Paulo: Martins Fontes, 2004.

BRASIL. Ministério da Educação e do Desporto. Parâmetros curriculares nacionais: Língua Portuguesa - $\mathbf{1}^{\mathbf{o}}$ e $2^{\mathbf{o}}$ ciclos. Brasília: MEC/SENTEC, 1996.

BRASIL. Ministério da Educação e do Desporto. Parâmetros curriculares nacionais: Língua Portuguesa - 3o e $4^{\circ}$ ciclos. Brasília: MEC/SENTEC, 1998.

BRASIL. Ministério da Educação e do Desporto. Parâmetros curriculares nacionais: Linguagens, Códigos e suas Tecnologias - Ensino Médio. Brasília: MEC/SENTEC, 2000 .

BRASIL. Ministério da Educação e do Desporto. PCN +: Orientações Educacionais Complementares aos Parâmetros Curriculares Nacionais. Linguagens, Códigos e suas Tecnologias - Ensino Médio. Brasília: MEC/SENTEC, 2002. 
BRASIL. Ministério da Educação e do Desporto. Orientações Curriculares para o Ensino Médio. Linguagens, Códigos e suas Tecnologias. Brasília: Brasília : Ministério da Educação, Secretaria de Educação Básica, 2006.

DALVI, M.A. , REZENDE, N.L. e JOVER-FALEIROS (orgs.) Leitura de literatura na escola. São Paulo: Parábola, 2013.

JOUVE, Vincent. A leitura como retorno a si: sobre o interesse pedagógico das leituras subjetivas. Leitura subjetiva e ensino de literatura. ROUXEL, A., LANGLADE, G. e REZENDE, N.L. (orgs.). São Paulo: Alameda, 2013.

LAURIA, Maria Paula Parisi. Livro didático de Português: entre as concepções de ensino, os trilhos da lei e as sendas do texto. Tese (Doutorado). São Paulo, 2004. Faculdade de Educação. Universidade de São Paulo (USP).

MAZAURIC, Catherine. Les moi volatils des guerrtre es perdues: a leitura, construção ou desconstrução do sujeito?. In: Leitura subjetiva e ensino de literatura. Trad. Gabriela Rodella de Oliveira. São Paulo: Alameda, 2013.

ROUXEL, A., LANGLADE, G. e REZENDE, N.L. (orgs.). Leitura subjetiva e ensino de literatura. São Paulo: Alameda, 2013.

ROUXEL, Annie. Aspectos metodológicos do ensino de literatura. In: Leitura de literatura na escola. Trad. Neide Luzia de Rezende. São Paulo: Parábola, 2013.

TARDIF, Maurice. Saberes profissionais dos professores e conhecimentos universitários. Revista Brasileira de Educação. Rio de Janeiro: ANPED. No. 13. Jan/Fev/Mar/Abr, 2000. 